\title{
Analysis of the Risk Factors on Chinese Korean Migration
}

\author{
Zhang Jingyue, Yang Xue \\ Northeast Asian Studies Academy of Jilin University, Changchun, Jilin, China
}

Email address:

zjyz13@mails.jlu.edu.cn (Zhang Jingyue)

\section{To cite this article:}

Zhang Jingyue, Yang Xue. Analysis of the Risk Factors on Chinese Korean Migration. Humanities and Social Sciences.

Vol. 3, No. 5, 2015, pp. 280-285. doi: 10.11648/j.hss.20150305.29

\begin{abstract}
Since the fifth population census, the number of Chinese Korean population has declined for more than 10 years. And the number of Chinese Korean at their main settelments in northeast of China has declined for more than 20 years. The main reason for the phenomenon of Chinese Korean population's negative growth is migration.Domestic migration leads to the decline of Chinese Korean population in northeast of China, and cross-border migration gives rise to the negative growth of Chinese Koreans allover of China. Chinese Korean migration affected the economic and society of their settelments. Many Chinese Koreans went to the coastal cities of China after the reform and open-up policy, and the number of Chinese Korean women who married with Koreans is increasing. The data sources of this paper are population census data and a survey concerning the migrated population conducted in minority areas in 2012 by ChineseNational Population and Family Planning Commission.We analyze the risk factors through descriptive statistical analysis and Logistic regressions. The results suggest that the risk of female migration is higher than male; the main migrants focus on the ages of 31-50;the migration tendency of single people is greater than people have married; Migration tendency increase with educational degree;population with medium educational degree prefer cross-border migration, and people with high educational degree prefer migration in domestic;migration tendency of people with agriculture household is higher than non-agriculture.
\end{abstract}

Keywords: Migration, Chinese Korean, Out-Migration, Negative Growth

\section{中国朝鲜族人口迁移风险因素分析}

\author{
张竞月, 杨雪 \\ 吉林大学东北亚研究院, 长春, 吉林, 中国
}

邮箱

zjyz13@mails.jlu. edu.cn（张竞月）

摘要: 从 2000 年第五次人口普查开始, 中国朝鲜族人口数量全面下降。而朝鲜族人口最多的东北三省, 朝鲜族人口负 增长已超过 20 年。造成朝鲜族人口数持续负增长现象的主要原因就是朝鲜族人口迁移。中国境内迁移主要造成东北三 省朝鲜族人口下降, 而造成中国朝鲜族人口下降的主要原因是朝鲜族人口的跨境迁移。朝鲜族地区人口迁移对当地社 会经济有着重要影响。改革开放以后, 朝鲜族劳动力开始大量向中国沿海开放城市流动, 同韩国人结婚的朝鲜族女性 数量不断增加, 这对中国朝鲜族人口产生直接影响。本文将使用第六次人口普查最新数据和 2012 年民族地区流动人口 监测报告数据, 通过描述性统计分析、比较研究和二分类、多分类Logistic 回归等方法对朝鲜族人口迁移的风险因素 进行分析, 结果显示, 虽然男性迁移的比例略高于女性, 但是女性迁移的倾向大于男性; 迁移人群主要以 $31-50$ 岁的青 壮年劳动力人口为主; 未婚人群的迁移倾向大于已婚人群; 教育程度越高, 迁移倾向越高, 中等教育程度人群偏向于 跨境迁移，高等教育程度人群则倾向于中国境内迁移; 农业户口持有者的迁移倾向高于非农业户口持有者。

关键词: 迁移, 朝鲜族, 跨境迁移, 人口负增长 


\section{1. 引言}

中国拥有 55 个少数民族，每个民族都有各自的形成历 史和独特的发展特点。朝鲜族是明末清初陆续从朝鲜半岛 迁入中国的, 是长期在中国独特的历史环境和地理环境 中形成的民族共同体 [1]。1949年新中国成立后, 朝鲜移 民正式成为中华人民共和国公民, 而朝鲜族也正式成为中 国55个少数民族中的一员。作为中国少数民族的一员，朝 鲜族有着与其他民族不同的形成历史和发展特点, 由于中 国朝鲜族人口有着典型的代表性和超前性, 对于研究中国 其他少数民族人口发展趋势有重要的参考作用, 所以朝鲜 族人口问题历来受到人口学家和民族社会学家的高度重 视 [2]。

\section{2. 研究基础}

近年来, 随着人口迁移问题研究的进一步深入, 一些 人口学者认识到朝鲜族地区人口迁移对朝鲜族聚居地区 社会经济有着重要影响。尹豪、朴美兰等学者对 20 世纪 90 年代以来, 延边朝鲜族的人口总量出现了自然负增长 的现象进行了研究, 研究表明人口迁移是造成人口负增 长的重要因素 [3] [4]。薛宝生、李春敏、王亚东、黄桂 兰在研究了吉林省延边州人口迁移的总体趋势后指出: 中国朝鲜族的人口发展经历了漫长而曲折的过程。从历 史上看, 随着中国朝鲜族人口聚居区域经济和社会的不 断发展变化, 朝鲜族人口的发展曲线呈现时增时减的波 浪状, 其人口迁移和人口分布状况也很复杂, 迁移人口数 量大, 迁移频率高, 近些年有些朝鲜族聚居区域已经打破 了传统的居住模式, 出现了由聚居向散居发展的现象 [5]。 林明鲜等运用交换理论, 以延边朝鲜族女性的涉外婚姻 为例, 探讨婚姻中的资源与交换之间的关系 [6]。改革开 放以来, 中国社会主义市场经济体制不断发展和完善, 中 国朝鲜族的经济发展意识浓厚起来, 由于朝鲜族与韩国 语言和文化相似, 中国朝鲜族人群利用其先天的语言文 化优势开始通过打工、求学和跨国婚姻等方式走出国门, 朝鲜族人口迁移日渐频繁。起初中国朝鲜族人口大部分 是迁入韩国, 但近些年, 随着中国社会经济的不断进步, 与其他国家外交关系的不断发展, 朝鲜族劳务输出更加 活跃, 一些朝鲜族人甚至迁移到俄罗斯、日本、美国等三 十几个国家和地区 [7]。杨雪、张竞月通过对延边朝鲜族 迁出人口进行分析后得出, 越来越多的女性人口开始走 出家庭, 参与到社会劳动中来 [8] [9], 很多女性迁移到 韩国打工, 有些甚至通过婚姻迁移永久的离开了居住地 [10], 女性人口迁出对朝鲜族人口负增长的作用日益增 加。

\section{3. 朝鲜族人口总体情况概述}

目前东北三省的中国朝鲜族人口占全国朝鲜族人口 的比例相对较高, 但是从历次人口普查朝鲜族人口的数据 对比中可以看出, 自 2000 年以后, 东北三省的朝鲜族人口
数量逐年下降, 占全国朝鲜族人口的比例也持续下降。传 统的朝鲜族聚居区的朝鲜族人口比例也是不断地下降, 以 延边朝鲜族自治州为例, 1953年延边州的朝鲜族人口比例 为 $60.17 \%$, 汉族比例为 $37.4 \%$, 而到了和 2010 年, 汉族比 例变成 $64.56 \%$, 而朝鲜族人口比例则变成 $32.45 \%[12]$ 。

自2000年第五次人口普查以后, 中国朝鲜族人口开始 全面下降, 1953年第一次人口普查时, 中国的朝鲜族人口 为 112 万, 自此次人口普查后中国朝鲜族人口数量持续攀 升, 1990年第四次人口普查时, 达到 192.3 万, 到 2000 年 第五次人口普查时, 中国朝鲜族人口为 192.4 万, 10 年间 基本上没有增加, 自2000年以后, 朝鲜族人口开始逐年下 降, 2010年第六次人口普查时, 中国朝鲜族人口下降到 183 万人 [13]。吉林省和黑龙江省的朝鲜族人口则是从第四次 人口普查后就开始下降。辽宁省的朝鲜族人口数则持续攀 升，直到2000年第五次人口普查后才略有下降。

朝鲜族人口下降的主要原因, 就是近年来朝鲜族人口 的迁移。朝鲜族人口的迁移率远高于全国平均水平和其他 主要民族的迁移率，为 $24.07 \%$ （全国平均水平为 $19.48 \%$, 汉族为 $20.01 \%$ ）。

朝鲜族人口的迁移形式主要分为省内迁移, 省际迁移 和跨境迁移。迁移原因主要分为务工经商、工作调动、学 习培训、随迁家属、投靠亲友、拆迁搬家、婚姻嫁娶和寄 挂户口等, 还有一些其他的原因。

朝鲜族的人口迁移流动主要表现为向中国大城市尤 其是沿海开放城市的流动和跨境劳务输出及涉外婚姻。在 中国境内, 朝鲜族的主要迁移目的地为京津地区、山东半 岛、华东地区和华南沿海地区等沿海较发达地区。跨境迁 移的目的地主要是韩国。

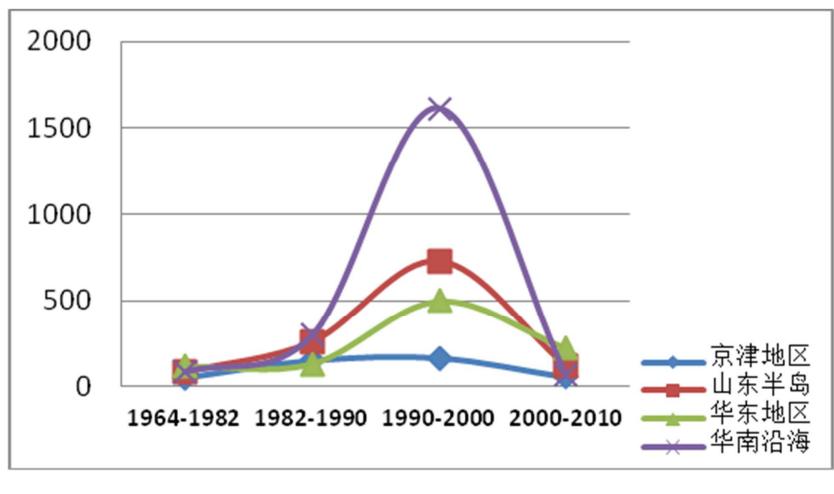

数据来源: 历次国家人口普查数据

图1 朝鲜族人口迁入地区朝鲜族人口增幅对比。

从图1可以看出, 1982年以前, 京津地区、山东半岛、 华东地区和华南沿海地区等较发达地区朝鲜族人口数变 化不大，1982年到1990年期间，除了京津地区朝鲜族人口 数增长速度较快, 其他地区朝鲜族人口数增长幅度不大, 这应该与改革开放政策有关, 改革开放以后, 很多朝鲜族 开始离开家乡出外打工, 由于京津地区是国家政治经济中 心, 大部分打工者会选择京津地区。1990年以后, 这四个 地区的朝鲜族人口增长迅速, 主要是由于 1992 年中韩建交 以后, 很多韩国人在中国沿海地区投资建厂, 朝鲜族人口 凭借较高的文化素质和先天的语言文化优势, 到这些地区 
的韩国企业务工。各地区朝鲜族人口增幅也是在 1990-2000年这个阶段增长最快, 其中华南地区最为显著, 增幅达到1612.44\%。

\section{4. 相关概念及研究方法}

根据中国户籍登记制度, 迁移的定义为官方户籍变动 的迁移, 要求户籍从原住地迁出并且迁入到迁移目的地 [9]。“迁移” 往往被定义为 “人口居住地从一个地方到另 一个地方的永久性变动 [12]. 户籍没有变动的迁移人口往 往被叫做流动人口, 无论这些流动人口在迁入地居住的时 间有多长, 他们依然被看做是原住地的居民 [6]。因此本 文中的迁移的概念与传统的迁移概念略有不同。本文中将 迁移定义为, 无论户籍是否变动, 只要一个人离开居住地 超过一个月, 便认定为是迁移人口。本文中所有的研究对 象都必须出生在中国。

朝鲜族的人口迁移流动主要表现为向中国大城市尤 其是沿海开放城市的流动和向外国的劳务输出及涉外婚 姻。改革开放以后, 朝鲜族劳动力开始大量向沿海开放城 市流动。向韩国劳务输出的朝鲜族人口中, 同韩国人结婚 的朝鲜族女性数量不断增加, 这对中国朝鲜族人口产生直 接影响。

本文将基于作者的前期研究成果所得到的结论, 使用 第六次人口普查最新数据和 2012 年中国国家卫计委民族 地区流动人口监测报告数据, 通过描述性统计分析、比较 研究和二分类、多分类Logistic 回归等方法对影响朝鲜族 人口迁移的影响因素进行分析研究, 总结中国朝鲜族人口 在中国境内流动和跨境流出状况的现状和特点, 量化研究 影响朝鲜族人口跨境流出的主要因素。下面将本文变量的 取值予以说明。

我们收集了每一名参与调查者的信息, 包括是否迁移, 迁移目的地, 年龄, 民族, 户口性质, 教育程度和婚姻状 态。

是否迁移：由本人回答或者家庭成员代为回答，已迁 出为 “是”, 未迁出则为 “否”;

迁入地类型: 分为省内迁移, 中国省际迁移和跨境迁 移三个类型;

年龄: 每位接受调查者的在接受调查时的年龄, 为了 更细致的分析出各个年龄段发生迁移的概率, 本文中将年 龄分为0-20岁，21-30岁，31-40岁，41-50岁，51-60岁， 61 岁及以上六个年龄段;

民族：本文中所有的调查对象均为朝鲜族;

户口性质：农业户口和非农业户口;

教育程度：分别为文盲及半文盲，小学文化程度，初 中文化程度; 高中文化程度和大学及以上文化程度;

婚姻状况: 分别为未婚, 已婚有配偶 (初婚、再婚), 已婚无配偶（离婚、丧偶）三个类型。

\section{5. 描述性统计分析}

本文的数据来自中国人口和计划生育委员会组织的 2012年民族地区流动人口调查, 本文主要使用调查中中国
朝鲜族人口的部分, 配合我们挨家挨户的调查和问卷的结 果。本文的样本是所有接受调查的朝鲜族人口, 包括已迁 移人口和未迁移人口, 样本包括 6718 人, 其中迁移人口为 2835 人, 占接受调查总人口的 $42.2 \%$ 。

\section{1. 迁移人口的特征}

表1 中国朝鲜族不同迁入地的迁移人口特征对比，单位:\%。

\begin{tabular}{lllll}
\hline & 省内 & 省际 & 跨境 & 合计 \\
\hline 男性 & 4.02 & 8.68 & 40.35 & 53.05 \\
女性 & 4.34 & 7.44 & 35.17 & 46.95 \\
$0-20$ 岁 & 1.55 & 1.38 & 0.49 & 3.42 \\
$21-30$ 岁 & 3.84 & 8.61 & 12.13 & 24.58 \\
$31-40$ 岁 & 1.16 & 3.81 & 22.75 & 27.72 \\
$41-50$ 岁 & 1.06 & 1.48 & 22.57 & 25.11 \\
$51-60$ 岁 & 0.31 & 0.78 & 13.12 & 14.21 \\
61岁以上 & 0.39 & 0.13 & 4.44 & 4.96 \\
未婚 & 5.43 & 10.02 & 22.72 & 38.17 \\
已婚有配偶 & 2.43 & 4.55 & 45.82 & 52.80 \\
已婚无配偶 & 1.09 & 0.96 & 6.98 & 9.03 \\
文盲半文盲 & 0.35 & 0.67 & 0.74 & 1.76 \\
小学 & 0.87 & 0.49 & 2.43 & 3.79 \\
初中 & 4.23 & 8.43 & 52.98 & 65.64 \\
高中 & 1.16 & 3.46 & 15.80 & 20.42 \\
大学及以上 & 1.76 & 3.07 & 3.56 & 8.39 \\
农业户口 & 6.98 & 14.11 & 64.48 & 85.57 \\
非农业户口 & 1.64 & 2.81 & 9.98 & 14.43 \\
\hline
\end{tabular}

资料来源：2012年中国国家卫计委民族地区流动人口监测报告数据

表 1 描述了在不同迁入地中国朝鲜族迁移人口的迁移 特征, 包括省内、省际和跨境迁出人口。朝鲜族迁移人口 的人口社会特征主要包括: 性别、年龄、婚姻状况、教育 程度、户口等。从性别特征来看, 男性总体迁移比例略高 于女性, 相对于其他民族来讲, 朝鲜族女性和男性的迁移 比例差距不大, 这说明越来越多的朝鲜族女性已经开始积 极的参加到社会劳动中, 不再是以家庭劳动为主的家庭妇 女类型。男性省际迁移和跨境迁移比例也高于女性, 但女 性省内迁移的比例略高于男性, 说明在选择迁移目的地的 时候, 女性往往会选择距离较短的目的地。从年龄段来看, 31-40岁区间的迁移人口所占比例最高, 其次分别是 41-50 岁区间和21-30岁区间，这三个年龄段的迁移人口比例之 和超过 $60 \%$ 。但是迁移到韩国的人口则以 $31-40$ 岁区间和 41-50岁区间年龄段为主, 两个年龄段迁移人口比例之和 约为 $45 \%$ 。无论迁移目的地是省内迁移、省际迁移还是跨 境迁移，迁移人群都主要集中在 31 岁-50岁区间。

从婚姻状况看, 已婚有配偶者的迁移率最高, 其次是 未婚者。未婚者的省际和省内迁移率较高, 已婚有配偶者 迁移到韩国的比例非常高。自从2007年韩国实行新的境外 人员务工政策以后, 中国朝鲜族去韩国打工更加容易, 越 来越多中国朝鲜族人口凭借先天的文化和语言优势去韩 国打工, 对于已婚者来讲, 在中国成立家庭以后, 通常会 选择一名家庭成员去韩国打工来改善家庭的经济状况。从 受教育程度看, 初中教育程度人口的迁移比例最高, 为 $65.64 \%$ 。在迁移到韩国的人口中, 也是初中教育程度人口 的比例最高, 因为在韩国为中国务工者提供的工作大部分 为比较简单机械的体力劳动, 不需要更高的文化素质, 但 
是文化素质也不能过低, 而教育程度处于中游的人口在中 国从事相同的工作收入远远少于韩国同样的工作, 所以很 多初中教育程度的人口选择去韩国打工。从户口性质看, 农业户口迁移者比例远远高于非农户口的迁移者, 很多非 农业户口的人在中国有稳定的工作，所以他们的迁移倾向 比较小, 而持有农业户口的人口主要居住在农村, 以种地 为生, 在中国的收入不稳定, 所以他们的迁移倾向远远大 于非农业户口人口。

\section{6. 模型和结果}

表2 朝鲜族人口是否迁移因素二分类Logistic回归模型。

\begin{tabular}{lll}
\hline & 发生比 & SE \\
\hline 性别 (女性) & $0.748^{* * * *}$ & 0.061 \\
年龄 (0-20) & & \\
$21-30$ & $5.771^{* * * * *}$ & 0.147 \\
$31-40$ & $13.445^{* * * * *}$ & 0.159 \\
$41-50$ & $7.105^{* * * *}$ & 0.162 \\
$51-60$ & $2.445^{* * * * *}$ & 0.167 \\
61 岁及以上 & $0.651^{*}$ & 0.176 \\
婚姻 (未婚) & & \\
已婚有配偶 & $0.462^{* * * *}$ & 0.122 \\
已婚无配偶 & $0.668^{* * *}$ & 0.091 \\
文化程度 (文盲/半文盲) & & \\
小学 & 0.672 & 0.209 \\
初中 & $1.659^{*}$ & 0.190 \\
高中 & $1.989^{* * *}$ & 0.199 \\
大学及以上 & $1.877^{*}$ & 0.217 \\
户口（非农业） & $1.135^{* * *}$ & 0.082 \\
\hline
\end{tabular}

注释: ${ }^{*} \mathrm{p}<0.05,{ }^{*} \mathrm{p}<0.01,{ }^{* * *} \mathrm{p}<0.001$ (Two-tail). 表中括号是参照组

资料来源：2012年国家卫计委民族地区流动人口监测报告数据

Logistic 回归模型是一种非线性的概率模型, 属于多 重变量分析范畴, 是社会学、统计学、医学、数量心理 学、市场营销等统计实证分析的常用方法 [9]。依据因变 量的取值情况, Logistic 回归模型分为二分类回归模型和 多分类回归模型。在二分类Logistic回归模型中, 因变量 只能取两个值, 而在多分类Logistic回归模型中, 因变量 则可以取多个值。

首先我们对调查数据进行二分类Logistic回归分析。 表2为二分类Logistic 回归模型分析结果。我们以是 否迁移为因变量 (参照组为未迁移人口), 以性别、年龄、 婚姻状况、文化程度和户口性质为自变量做二分类 Logistic回归模型。

统计分析结果显示, 女性的迁移倾向大于男性, 这也 符合我们之前的讨论, 越来越多的朝鲜族女性脱离家庭劳 动, 积极地参与到社会劳动中。年龄对中国朝鲜族人口迁 移的作用非常显著。最显著的是 31-40岁年龄段朝鲜族迁 移人口, 这一年龄段人群的迁移风险是0-20岁年龄段的 13 倍多, 相比之下, 51-60岁年龄段人群的迁移风险仅为 $0-20$ 岁人群的 2.4 倍, 而 60 岁以上人口的迁移倾向明显降低, 迁 移风险低于 0-20岁人口, 说明随着年龄的增长, 人们迁移 的风险也开始增加, 而到壮年之后这种风险会逐渐下降, 但仍高于少年儿童人口, 到了老年, 迁移风险降至最低,
中国的传统讲究 “落叶归根” , 老年人口受到身体状况和 传统思想的限制, 迁移倾向降低。

从表 2 中可以看出, 中国朝鲜族已婚人口的迁移风险 低于未婚人口。朝鲜族未婚迁移人口没有太多的负担, 具 有出外打工或学习的客观条件, 很多未婚女性更是希望通 过跨境迁移, 实现跨国婚姻, 从而取得韩国身份, 在韩国 生活。而已婚人群的迁移目的大多是想改善家庭的生活条 件, 都是出于经济方面的考虑, 已婚者在迁移前的考虑因 素多于未婚者, 所以已婚者的迁移倾向低于未婚者。随着 教育程度的提高, 迁移风险相对也越来越大。

从教育程度来看, 教育程度越高, 迁移风险越大, 高 中教育程度的迁移风险达到最高, 大学教育程度的迁移风 险又略有降低。一般来说, 迁移行为本身可以提高人口自 身的素质。因此, 在教育条件比较差的地区, 即使对人们进 行最初级的教育, 也能够产生有利于人口素质提高的连锁 反应[9]。农业户口居民的迁移倾向高于非农业户口，这 也与我们前文的讨论相符合。

接下来我们对调查数据进行多分类Logistic 回归分 析。

以迁入地类型为因变量 (参照组为未迁移人口), 以性 别、年龄、婚姻情况、受教育程度和户口性质为自变量做 多分类Logistic 回归, 结果如表3所示。

表3 朝鲜族人口迁入地决定因素多分类Logistic回归结果。

\begin{tabular}{|c|c|c|c|}
\hline & 省内 & 省际 & 跨境 \\
\hline 性别（女性） & $0.618^{* *}$ & $0.709^{*}$ & $0.776^{* * * *}$ \\
\hline \multicolumn{4}{|l|}{ 年龄 (0-20) } \\
\hline $21-30$ & 1. $968^{*}$ & 5. $770^{\text {*owk }}$ & $20.398^{* * * *}$ \\
\hline $31-40$ & 1. 441 & 6. $181^{\text {*atk }}$ & $72.725^{* * * *}$ \\
\hline $41-50$ & 0.938 & 1.745 & $38.525^{* * * *}$ \\
\hline $51-60$ & $0.179^{* * *}$ & 0.584 & $13.381^{* * * *}$ \\
\hline $61+$ & $0.148^{* * * *}$ & $0.044^{* \text { *ak }}$ & $3.534^{* * * * *}$ \\
\hline \multicolumn{4}{|l|}{ 婚姻（未婚） } \\
\hline 已婚有配偶 & $0.266^{* * *}$ & $0.186^{* \text { *ak }}$ & $0.575^{* * * *}$ \\
\hline 已婚无配偶 & $0.492^{* *}$ & $0.454^{* \text { **ak }}$ & $0.783^{*}$ \\
\hline \multicolumn{4}{|l|}{ 教育 (文盲半文盲) } \\
\hline 小学 & 1. 882 & $0.468^{*}$ & $0.517^{*}$ \\
\hline 初中 & 2. 378 & 1. 035 & 1. 499 \\
\hline 高中 & 2.544 & 1. 658 & 1. $724^{*}$ \\
\hline 大学及以上 & 6. $302^{* * *}$ & 2. $311^{*}$ & 1.005 \\
\hline 户口性质 (非农业) & 1. 092 & 1. $456^{*}$ & $1.308^{*}$ \\
\hline
\end{tabular}

注释: ${ }^{*} \mathrm{p}<0.05,{ }^{*} \mathrm{p}<0.01,{ }^{*}{ }^{*} \mathrm{p}<0.001$ (Two-tail). 表中括号是参照组 资料来源：2012年国家卫计委民族地区流动人口监测报告数据

分析结果显示, 无论迁移目的地为中国境内还是境外, 女性的迁移风险都高于男性。这与朝鲜族女性的跨国婚姻 有关, 很多女性迁移的目的就是嫁到韩国, 在韩国生活。 据统计, 到 2009 年为止, 中国朝鲜族女性婚姻移民者为 46639名, 占韩国婚姻移民总数的 $35.8 \%$ [14]。

31-40岁区间依然是跨境迁移的高风险人群, 是0-20 岁人口的 72 倍, 41-50岁区间的跨境迁移风险也很高, 是 0-20岁人口的38倍。而中国境内迁移风险人群则以 21-30 岁和31-40岁年龄段为主。可以看出, 年龄是影响迁移的主 要因素, 迁移人口主要以30-50岁之间的青壮年劳动力人口 为主。 
和未婚者相比较, 已婚人口迁移的风险较小, 已婚无 配偶人群的跨境迁移风险高于已婚有配偶的人群, 说明未 婚者和已婚无配偶人群迁移时所需考虑的因素较少, 牵挂 相对于已婚有配偶人群也较小。

虽然初中和高中教育程度的结果不显著, 但是就数值 看来, 受过教育的人口迁移到省外和国外的风险高于文盲 半文盲人口。大学及以上文化程度的人群中国境内迁移的 风险远远高于文盲半文盲人口, 这说明受过大学及以上教 育的人群在中国的城市可以找到比较收入和环境都比较 合适的工作, 他们不需要离乡背井的选择跨境打工。

农业户口持有者迁移的风险明显高于非农业户口持 有者。到韩国的风险也高于非农业户口持有者。农业户口 持有者在中国主要以务农为主, 收入不稳定, 而且在中国 很多方面与非农业户口持有者的待遇有一定的差别。对于 跨境迁移的人来说, 农业户口的限制作用已经不存在，与 非农业户口的差别也不明显, 这是农业户口持有者选择跨 境迁移的一个很大的动力。

\section{7. 结论与讨论}

改革开放以来, 大量朝鲜族人口迁移, 给中国朝鲜族 聚居区域经济、社会等各方面带来很多不利影响。

传统朝鲜族聚居地区对外劳务经济的发展刺激了当 地的消费, 扩大内需, 提高了当地的消费水平。对外劳务 经济的发展改变了朝鲜族传统的消费模式, 中国朝鲜族聚 居区是受 “韩流” 冲击最强烈的地方。韩国大众休闲文化 通过直接接触和媒介传播两种形式传播到朝鲜族聚居区, 对朝鲜族生活影响很大, 在我们的实地调查中发现, 基本 上所有的朝鲜族家庭都使用韩国进口商品, 很多女性的穿 着打扮都是 “韩剧” 中比较流行的穿着, 在传统朝鲜族聚 居区出现 “高消费、低储蓄”、“收入不高, 消费不低” 的消费模式。朝鲜族地区的消费模式使得有限的资源向第 三产业过度集中, 农业和工业发展受到冷遇, 造成经济总 量扩张缓慢, 经济发展滞后等问题。

朝鲜族聚居地区的土地管理出现两级分化现象。一方 面, 拥有的土地质量较好、所处地理位置较好, 而且交通 也比较方便的朝鲜族农民, 在外出务工时会把他们闲置的 土地出租给留守的朝鲜族农民或者未迁移的汉族农民, 这 为土地集约化运营提供了便利条件, 承租土地的农民可以 集中管理土地, 实现土地集约化管理和运营。另一方面, 很多朝鲜族聚居的村落土地质量比较差, 种植农作物产量 低, 还有些朝鲜族村落地理位置比较偏远, 交通不发达, 农作物运输困难, 这些地区的土地无人承租, 大片土地闲 置荒芜。

大量的朝鲜族青壮年劳动力迁移导致朝鲜族聚居地 区劳动力严重不足, “留守儿童” 问题突出。为减轻工作 压力, 许多外出工作的青壮年劳动力人口不愿也没有条件 让子女随迁, 边境乡村出现了大量的留守儿童, 长期无法 与父母生活在一起, 父爱和母爱的缺失对留守儿童的身心 造成极大伤害, 部分留守儿童长期缺乏安全感, 人生观和 价值观发生扭曲, 留守青少年犯罪率不断增加。
大量的朝鲜族人口迁移导致传统朝鲜族聚居地区日 益萎缩, 但在中国沿海及发达城市形成新的朝鲜族聚居 区。目前在北京、天津、青岛、烟台、深圳和东莞都有 新的朝鲜族人口聚居区。

迁移的朝鲜族女性日益增加, 朝鲜族女性的涉外婚姻 逐年增多, 导致边境地区适婚年龄的男女性别比严重失调, 严重的乡镇性别比甚至达到了 30: 1, 这在全国都是非常 罕见的。很多已婚年轻妇女长时间在国外打工，长期的夫 妻分离使婚姻的稳定性降低, 产生了一系列的婚姻问题。

老龄化问题严重。青壮年劳动力流失导致传统朝鲜族 聚居区空巢老人的养老问题遭遇难题。目前朝鲜族老年人 口养老主要以居家养老模式为主, 家中子女无法满足老年 人日常照顾和医疗看护等需要, 更无法关注老年人口的精 神和心理健康。

大量的朝鲜族人口迁移导致传统朝鲜族聚居地区产生 大量的 “空心村”, 这些 “空心村” 平常没有几户人常住, 甚至有的村子仅有不到十户村民居住。传统朝鲜族聚居地 区多处于东北边境地区, 人口大量减少给边境治安和国防 建设带来了很大的难度, 严重危及边疆社会治安和稳定。

传统朝鲜族聚居地区教育水平降低, 医疗卫生水平低 下。朝鲜族人口大量流动和人口自然增长率的急剧下降, 使朝鲜族教育面临困境。朝鲜族中小学在校生日益减少。 许多学校因生源不足而被迫关闭或合并, 很多朝鲜族学生 不得不选择异地教育, 有些学生要走很远的路去上学, 有 些学生只能寄宿在学校, 定期回家。朝鲜族中小学校的日 益萎缩, 严重影响了边境朝鲜族青少年的教育事业。另外, 新的沿海发达地区的朝鲜族聚居区的朝鲜族儿童集中教 育也面临挑战。

另外, 边境医疗卫生状况也不容乐观。边境村里基本 没有配套的医疗卫生条件, 边民最近也要去附近的镇上看 病, 而地处边境的乡镇的卫生院条件相当有限, 使患者的 正常治疗受到影响。

\section{致谢}

本篇论文受中国国家社会科学基金项目 “人口迁移与 延边朝鲜族人口负增长关系研究” (13BRK023) 和中国吉 林大学创新研究项目 “中国少数民族地区人口迁移与发展 研究”（2015054）项目资助。

\section{参考文献}

[1] 严海玉. 中国朝鲜族入籍的历史过程 $[\mathrm{J}]$. 黑龙江民族从刊, 2007 , (4) : 42-45。

[2] 吴天喜. 中国朝鲜族人口问题浅论 [J]. 黑龙江民族从刊, 2001, (3) : 104-105。

[3] 尹豪. 人口学导论 [M]. 北京: 中国人口出版社。

[4] 朴美兰. 20 世纪 90 年代以来延边朝鲜族人口负增长原因探 析 [J]. 东疆学刊, 2010, 27 (1): 55-63。 
[5] 薛宝生, 李春敏, 王亚东, 黄桂兰. 论朝鲜族人口的可持续 发展 $[J]$. 人口学刊, $2000,122(4): 39-42$ 。

[6] 林明鲜. 婚姻行为中的资源与交换一以延边朝鲜族女性的 涉外婚姻为例 $[J]$. 人口研究, $2006,30(3), 50-55$ 。

[7] 王化波, 王釒鍂. 延边朝鲜族人口迁移的影响因素研究 [J]. 人口学刊, 2011, (2)：69-74。

[8] YangXue, WangXiaofeng \& LiuWeijiang. Outflows of Chinese Koreans in Yanbian Prefecture. Asian and Pacific Migration Journal, 2011, $20(3-4)$, 1-13.

[9] YangXue \& ZhangJingyue. Migration by Chinese Korean Women. Journal of Women's Studies, 2014, 20(4), 95-121.
[10] 王化波. 延边朝鲜族妇女生育意愿的影响因素分析 [J].人 口学刊, 2005, 151(3)，42-45。

[11] Goldstein \& Alice \& Sidney Goldstein \& Shenyang Guo . Temporary Migrants in Shanghai Households. Demography, 1991, 28 (2) :275-291.

[12] 2010年延边人口统计年鉴 [M].2012延边:延边统计局。

[13］2010年中国人口统计年鉴 [M]. 2012, 北京：国家统计局。

[14] 全信子, 同源异流的文化情结一中韩国际婚姻中朝鲜族女 性婚姻移民现象探析 [M]，2006，北京：学苑出版社。 